\title{
Pigment production by Lancefield-group-B streptococci (Streptococcus agalactiae)
}

\section{J. W. TAPSALL*}

\author{
Division of Hospital Infection, Central Public Health Laboratory, 175 Colindale Avenue, Colindale, \\ London NW9 $5 H T$
}

\begin{abstract}
Summary. Cells of group-B streptococci harvested in the late exponential phase of growth and suspended in starch-glucose phosphate-buffered saline extractor solution were observed to form and release pigment into solution. Filtrates of these solutions were analysed spectrophotometrically and two varieties of pigment were detected. Pigment, when freshly produced or in the presence of starch, had four absorption peaks at $520,485,455$ and $435 \mathrm{~nm}$. If albumin was substituted for starch in the extractor solution or if the starch-pigment complex was disrupted by treatment with amylase or by boiling, the four-peak pigment rapidly and irreversibly degraded to a second type with a single absorption band at $415 \mathrm{~nm}$. The pigments formed by washed cell suspensions had absorption spectra identical to those produced by pigment formed during growth in Todd-Hewitt Broth. The formation and release of soluble pigment appeared to be an active metabolic process; a carrier molecule and an energy source were both required. Pigment yields were increased when the $p \mathrm{H}$ of the extractor solution was in the range 7.0-7.4 and when $\mathrm{Mg}^{2+}$, but not other divalent cations, was present. No differences in yield or type of pigment were observed when pigment was formed in anaerobic conditions. These findings support an earlier observation that group-B streptococcal pigment resembles a $\beta$ carotenoid. There is some added support for the suggestion that haemolysin and pigment production by these organisms are closely linked characteristics.
\end{abstract}

\section{Introduction}

Interest in Lancefield-group-B streptococci has been stimulated by the recognition of their role in neonatal infections. They characteristically produce an orange-red pigment and early descriptions recorded pigment formation in strains from bovine and human infections (Orla-Jensen, 1919). The phenomenon of pigment production has attracted increased attention principally because it serves as a basis for the identification of this group of streptococci (Fallon, 1974; Merritt and Jacobs, 1976; Merritt et al., 1976; Islam, 1977; Waitkins, 1983). Amongst streptococci isolated in clinical laboratories, pigment has been produced only by group-B streptococci (Fallon, 1974; Noble et al., 1983), although a pigment has been characterised from a strain of Streptococcus faecium from soil (Taylor and Davies, 1974). Group-B streptococci were originally thought to produce pigment only in anaerobic conditions and in the presence of starch

Received 1 Apr. 1985; accepted 1 May 1985.

* Present address: Department of Microbiology, The Prince of Wales Hospital, Randwick, N.S.W. 2031 Australia.
(Durand and Giraud, 1923) but it has been shown subsequently that whereas these conditions are beneficial, they are not essential for pigment production (Fallon, 1974; Merritt and Jacobs, 1976; Haug and Soderlund, 1977).

The nature of the pigment has also been examined. Haug and Soderlund (1977) neutralised acid precipitates of pigment derived from broth cultures and demonstrated a single absorbance peak at 420 $\mathrm{nm}$ by spectrophotometric analysis. Merritt and Jacobs (1978) located the pigment in the cell membrane by differential centrifugation of sonicated cells and dispersed the membrane fraction in water. This material and phenol-glycerol extracts of whole cells produced absorption spectra with peaks at $435,455,485$ and $525 \mathrm{~nm}$. Comparison of these spectra with those of carotenoid pigments led these workers to suggest that group-B streptococcal pigment was a $\beta$-carotenoid.

In studies of the haemolysin of group-B streptococci by the methods of Marchelewicz and Duncan (1980) it was observed that an orange pigment was formed. The present study compared the pigment produced by washed-cell suspensions with that 
formed by organisms grown in liquid media. The relationship between the two pigment types previously described and the role of carrier molecules in pigment production was investigated.

\section{Materials and methods}

\section{Organisms}

The group-B streptococci used in this study were the pigment-producing strain NCTC 8017 (type III) and its non-pigmented variant, NCTC 8020 , as a control.

\section{Culture media and growth conditions}

Todd-Hewitt Broth (Oxoid) modified by the addition of Neopeptone (Difco, Detroit, USA) $1 \%$ and phosphate buffer $\left(\mathrm{Na}_{2} \mathrm{HPO}_{4} \cdot 2 \mathrm{H}_{2} \mathrm{O} 0 \cdot 074 \mathrm{~g} / \mathrm{L}\right.$ and $\mathrm{NaH}_{2} \mathrm{PO}_{4} \cdot 2 \mathrm{H}_{2} \mathrm{O}$ $0.013 \mathrm{~g} / \mathrm{L}$ ) (THB) was the medium employed. In certain experiments THB was further modified by the addition of soluble starch (BDH, Poole, Dorset) $0.1 \% \mathrm{w} / \mathrm{v}$ or bovine serum albumin (Sigma) $5 \%$ w/v. Fifty ml of the medium was seeded with cultures grown overnight on horse-blood agar and then incubated in an atmosphere of $\mathrm{CO}_{2} 2.5 \%$ in air at $37^{\circ} \mathrm{C}$.

Analysis of pigment in culture supernates and preparation of washed bacterial cell suspensions

The broth cultures were incubated to the stationary phase of growth $(18 \mathrm{~h})$ and then centrifuged. The supernate were passed through a membrane filter of pore size $0.45 \mu \mathrm{m}$ and the bacterial cell pellets washed in phosphate-buffered saline (PBS) $(0.06 \mathrm{M}$ phosphate) $p \mathrm{H}$ $7 \cdot 0$, unless otherwise specified. After washing the suspensions were again centrifuged and the PBS supernates filtered as before.

In separate experiments the inoculated THB was incubated to the late exponential phase of growth $(c .5 \mathrm{~h})$ when the turbidity of the culture reached an optical density of 0.8 at $640 \mathrm{~nm}$ on an SP8-100 spectrophotometer (Pye-Unicam, Cambridge). These cultures were centrifuged, filtered and washed in PBS (as above).

The filtrates of the THB cultures and PBS washings were examined for absorbance at wavelengths from 700 to $375 \mathrm{~nm}$ in a SP8-100 scanning spectrophotometer (PyeUnicam, Cambridge). The pigment was quantitated by measuring absorbance at specified absorption peaks on the same instrument.

\section{Extractor solutions}

The extractor solution used for suspending the washed bacterial cell pellets was a starch-glucose solution in PBS. The concentrations of soluble starch were $0 \cdot 1-1 \%(\mathrm{w} / \mathrm{v})$ and those of glucose $0 \cdot 1-2 \%(\mathrm{w} / \mathrm{v})$. In some experiments bovine serum albumin $5 \% \mathrm{w} / \mathrm{v}$ was substituted for starch and on other occasions maltose was substituted for glucose. PBS solutions were prepared with a range of $p \mathrm{H}$ values and molarities. The molarity for phosphate in the
PBS was in the range $0 \cdot 06-0 \cdot 01 \mathrm{M}$. At each of the different molarities, PBS solutions were prepared in the $p \mathrm{H}$ range 5.8-7.8. The divalent cations $\mathrm{Ca}^{2+}, \mathrm{Co}^{2+}, \mathrm{Cu}^{2+}, \mathrm{Fe}^{2+}$, $\mathrm{Mg}^{2+}$, and $\mathrm{Zn}^{2+}$ in $0.001 \mathrm{M}$, concentrations were added separately to the solution as appropriate salts.

Determination of conditions for formation and release of pigment from washed bacterial cell suspensions

The suspension of the PBS-washed cell pellet in the extractor solution was usually incubated at $37^{\circ} \mathrm{C}$ for 15 min. Incubation temperatures of $0^{\circ}, 22^{\circ}$ and $60^{\circ} \mathrm{C}$ and incubation times of 5-60 min were used in some experiments. The volume of extractor fluid used was $2.5 \mathrm{ml}(5 \%$ of the original culture volume) and in certain experiments this was increased to 5 or $10 \mathrm{ml}$. Incubation was usually in air but some experiments were performed in an anaerobic atmosphere $\left(\mathrm{N}_{2} 90 \%, \mathrm{CO}_{2} 10 \%\right)$ obtained by means of a Kaltec SJ3 anaerobic chamber (Edwardston, South Australia). The extractor solution and the bacterial cell pellet were equilibrated in the chamber for $30 \mathrm{~min}$ before mixing. After the incubation period the suspension was centrifuged and the supernate filtered and analysed spectrophotometrically (as above).

\section{Results}

\section{Pigment formation in broth cultures}

Stationary-phase cultures of strain NCTC 8017 in THB formed a deposit with a reddish-brown colour. This pigment was present in filtrates derived

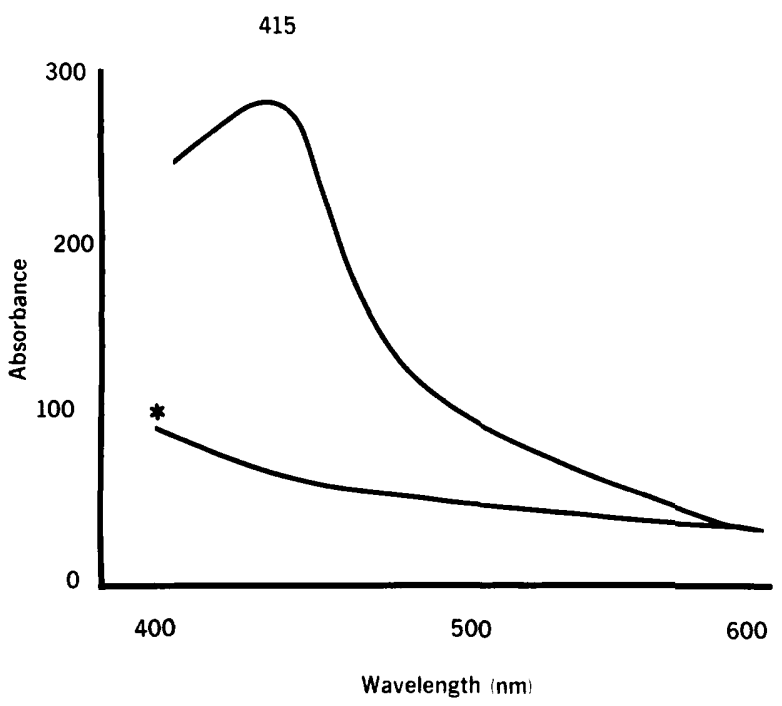

Fig. 1. - Absorbance spectra obtained with filtrates of stationary-phase cultures of pigmented group-B streptococcus NCTC 8017 and its non-pigmented variant NCTC $8020^{*}$ grown in modified Todd-Hewitt broth without starch. 
from the culture supernates and from PBS washings of deposits. Spectrophotometric analysis gave a single absorbance band at $415 \mathrm{~nm}$ (single-peak pigment) (fig. 1). Addition of starch $0 \cdot 1 \%(\mathrm{w} / \mathrm{v})$ to the THB resulted in the formation of an orange-red pigment in the stationary-phase culture supernates. Filtrates of these supernates gave absorption spectra with peaks at $520,485,455$ and $435 \mathrm{~nm}$ (fourpeak pigment), but no absorbance peak at $415 \mathrm{~nm}$ (fig. 2).

Late-exponential-phase cultures of strain 8017 in THB formed a tan coloured deposit. No pigment was detected in culture supernate harvested in this phase of growth and PBS washings of the deposit did not show absorbance peaks on spectrophotometric analysis. The control strain NCTC 8020 did not produce visible pigment nor were absorbance peaks detected on examination of this strain in conditions identical to those used for strain NCTC 8017.

Pigment formation by bacterial cell deposits suspended in extractor solutions

Characteristics of the pigment. When washed bacterial cells obtained from late-exponential-phase

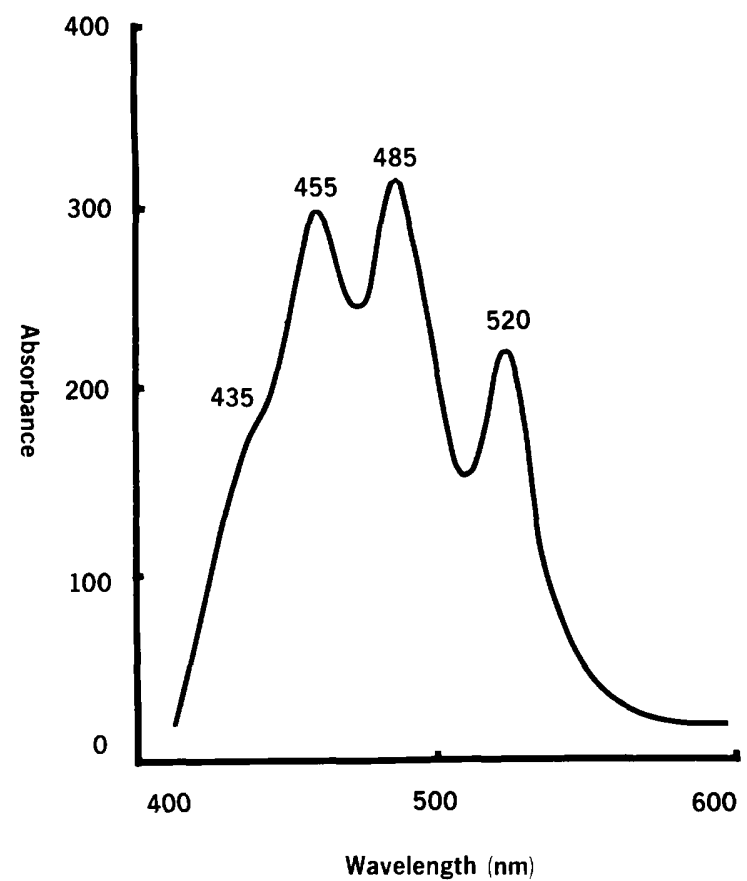

Fig. 2. - Absorbance spectrum obtained with filtrate of stationary phase culture of pigmented group B streptococcus NCTC 8017 grown in modified Todd-Hewitt broth containing soluble starch $0.1 \% \mathrm{w} / \mathrm{v}$. A similar absorbance spectrum was obtained with filtrates of suspensions of bacterial cell deposits incubated in glucose-starch-PBS extractor solutions. cultures of strain NCTC 8017 were suspended and incubated in a starch-glucose extractor solution, an orange pigment was formed. Spectrophotometric analysis of filtrates containing this starch-associated pigment produced the same absorption spectrum as the pigment present in filtrates of starchcontaining broth cultures, namely, peaks at 520 , 485,455 and $435 \mathrm{~nm}$ (fig. 2). No single-peak (415 $\mathrm{nm}$ ) pigment was detected in these filtrates and no absorbance peaks were detected in filtrates of cell suspensions derived from strain NCTC 8020.

Substitution of albumin $5 \%$ for starch in the extractor solution also resulted in the formation of pigment, but analysis of filtrates obtained after incubation for $30 \mathrm{~min}$ in albumin extractor revealed pigment with a single absorbance peak at $415 \mathrm{~nm}$ only (fig. 3).

Effect of composition of extractor fluids on pigment formation and release by washed cell suspensions. The formation and release into solution of four-peak pigment required the presence of both starch and glucose (table I). No pigment was detected in the filtrates of the suspensions when starch or glucose or both were deleted from the extractor solution. Addition of the missing component(s) to the deficient suspension(s) was accompanied by the formation and release of four-peak pigment after reincubation. The colour present in the cell deposit after incubation in extractor solution was also noted and compared with the colour of cells held in PBS in the same conditions. Cells suspended in starch-glucose-PBS or starch-PBS formed deposits similar in colour to those held in

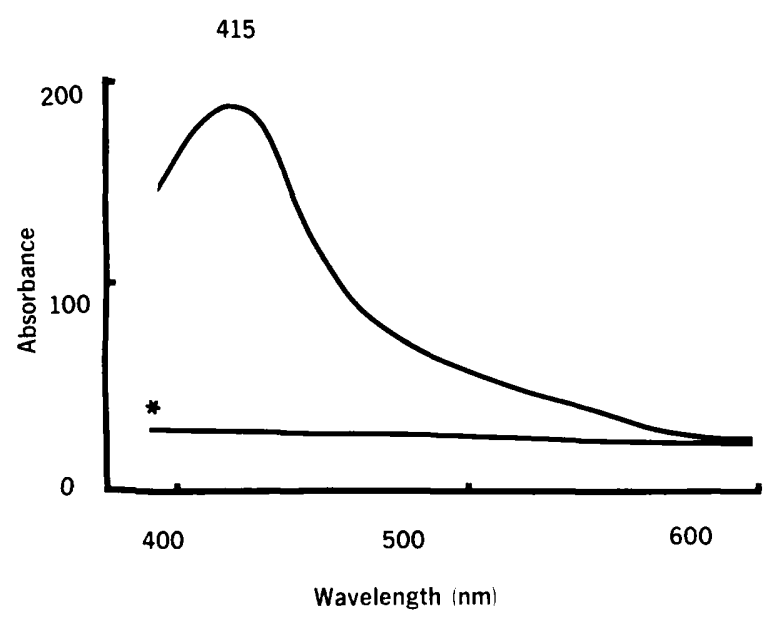

Fig. 3. - Absorbance spectra obtained with filtrates of suspensions of group-B streptococci NCTC 8017 and NCTC 8020* incubated in albumin-glucose-PBS extractor solutions. Incubation time $30 \mathrm{~min}$ at $37^{\circ} \mathrm{C}$. 
Table I. Pigment formation by cells of group-B streptococcus NCTC 8017 incubated in starch-glucose-PBS

\begin{tabular}{lrrrr} 
& \multicolumn{4}{c}{ Absorbance at (nm) } \\
\cline { 2 - 5 } & 435 & 455 & 485 & 520 \\
\hline Conditions of extraction & 580 & 850 & 855 & 580 \\
\hline Standard procedure* & & & & \\
Extractor solution with & 0 & 0 & 0 & 0 \\
$\quad$ starch omitted & 0 & 0 & 0 & 0 \\
glucose omitted & 645 & 970 & 975 & 655 \\
$0.001 \mathrm{M} \mathrm{Mg} \mathrm{Mg}^{2+}$ & 0 & 0 & 0 & 0 \\
Preincubation of cells in & & & & \\
$0.066 \mathrm{M}$ sodium iodoacetate & & & & \\
Temperature of incubation & & 0 & 0 & 0 \\
$0^{\circ} \mathrm{C}$ & 125 & 175 & 175 & 125 \\
$22^{\circ} \mathrm{C}$ & 0 & 0 & 0 & 0 \\
$60^{\circ} \mathrm{C}$ & & & & \\
\hline
\end{tabular}

* Standard procedure:extraction with phosphatebuffered saline $0.06 \mathrm{M}, p \mathrm{H} 7.0$ containing starch $0.1 \%$ $\mathrm{w} / \mathrm{v}$ and glucose $1 \% \mathrm{w} / \mathrm{v}$; incubation time $15 \mathrm{~min}$ at $37^{\circ} \mathrm{C}$.

PBS whereas the deposits of cells incubated in glucose-PBS were deeper brown.

The requirement for glucose for the formation and release of pigment suggested that this may be an active metabolic process. To investigate this hypothesis further, the bacterial cell suspension was preincubated with a $0.066 \mathrm{M}$ concentration of the metabolic inhibitor sodium iodacetate (Sigma) in PBS for $30 \mathrm{~min}$ at $37^{\circ} \mathrm{C}$ before mixing with the extractor solution. No pigment formation was detected in these conditions (table I) whereas a control cell suspension, preincubated in PBS without iodoacetate, formed pigment in expected amounts.

The presence of $0.001 \mathrm{M} \mathrm{Mg}^{2+}$ in the extractor solution increased yields of four-peak pigment by approximately $10 \%$ (table I). No increase in pigment formation was obtained in the presence of $0.001 \mathrm{M} \mathrm{Ca}^{2+}, \mathrm{CO}^{2+}, \mathrm{Cu}^{2+} \mathrm{Fe}^{2+}, \mathrm{Mn}^{2}$ or $\mathrm{Zn}^{2+}$.

No differences were detected in the amount of pigment present in filtrates of extractor solutions containing starch $0 \cdot 1,0.5$ or $1 \% \mathrm{w} / \mathrm{v}$. The standard concentration of starch used was $0.1 \%$.

Table II shows the effects of alteration of the glucose concentration in the extractor solution. An increase in glucose concentration from $0 \cdot 1$ to $1 \% \mathrm{w} /$ $v$ led to higher yields of pigment. Further increases in the concentration of glucose to $2 \%$ did not increase pigment yields. A $1 \%$ concentration of glucose was used in subsequent experiments. Substitution of maltose for glucose did not alter pigment yields.
Table II. Effect of glucose concentration of extractor solution* on pigment formation by washed cell suspensions of group B streptococcus NCTC 8017

\begin{tabular}{lrrrr} 
& \multicolumn{4}{c}{ Absorbance at (nm) } \\
\cline { 2 - 5 } $\begin{array}{l}\text { Glucose percentage (W/V) } \\
\text { of extractor solution }\end{array}$ & 435 & 455 & 485 & 520 \\
\hline Nil & 0 & 0 & 0 & 0 \\
$0 \cdot 1$ & 155 & 165 & 165 & 125 \\
$0 \cdot 25$ & 315 & 410 & 405 & 280 \\
$0 \cdot 5$ & 355 & 435 & 455 & 335 \\
1 & 365 & 480 & 455 & 310 \\
2 & 360 & 475 & 435 & 300 \\
\hline
\end{tabular}

* Extractor solution: PBS 0.01M for phosphate, $p \mathrm{H}$ $7 \cdot 0$, with $\operatorname{starch} 0 \cdot 1 \% \mathrm{w} / \mathrm{v}$.

Effect of physical conditions on the formation and release of pigment by washed cell suspensions. The formation and release of pigment was maximal at $37^{\circ} \mathrm{C}$; lesser amounts were formed at $22^{\circ} \mathrm{C}$ and no pigment was produced at $0^{\circ} \mathrm{C}$ or $60^{\circ} \mathrm{C}$ (table I).

Table III shows the effect of the $p \mathrm{H}$ of the extractor solution on pigment yields. Cell suspensions were washed in PBS with the same $p \mathrm{H}$ as that of the extractor fluid used. Pigment yields were maximal in the $p \mathrm{H}$ range $7 \cdot 0-7.4$ and progressively lower amounts of pigment were obtained as the $p \mathrm{H}$ of the extractor fluid departed from this range; relatively little pigment was found at $p \mathrm{H} 5.8$ or 7.8 . Increasing the molarity (for phosphate) of the PBS also increased pigment yields. This effect is shown in table II, line 5 (pigment production in $0.01 \mathrm{M}$ buffer) and table III, line 4 (pigment yields under similar conditions but in $0.06 \mathrm{M}$ buffer).

With starch-containing extractor solutions, progressively more pigment was formed as the time of incubation was extended to $60 \mathrm{~min}$. Formation and release of pigment occurred rapidly; visible pigment was present after incubation for $2 \mathrm{~min}$ at $37^{\circ} \mathrm{C}$. Similarly, with albumin-containing extractor solutions, increasing amounts of pigment were formed and released with longer incubation times. However, when albumin was employed for shorter incubation periods ( 5 or $15 \mathrm{~min}$ ), peaks at 520 and $485 \mathrm{~nm}$ were present in addition to the 415 peak (fig. 4) (see below).

No significant differences were noted between pigment extracted in air and that extracted anaerobically in regard to quantity or pigment type. In particular, pigment was not preserved in the fourpeak form when albumin was the carrier molecule and no differences were noted in this respect 
Table III. Effect of $p H$ of extractor solution* on pigment formation by washed cell suspensions of group B streptococcus NCTC 8017

\begin{tabular}{lllll} 
& \multicolumn{4}{c}{ Absorbance at (nm) } \\
\cline { 2 - 5 } $\begin{array}{l}\text { pH of extractor } \\
\text { solution* }\end{array}$ & 435 & 455 & 485 & 520 \\
\hline $5 \cdot 8$ & 110 & 165 & 190 & 150 \\
$6 \cdot 2$ & 245 & 365 & 375 & 265 \\
$6 \cdot 6$ & 355 & 550 & 625 & 470 \\
$7 \cdot 0$ & 580 & 850 & 855 & 580 \\
$7 \cdot 4$ & 575 & 835 & 850 & 575 \\
$7 \cdot 7$ & 120 & 165 & 170 & 115
\end{tabular}

* Extractor solution: PBS $0.06 \mathrm{M}$ for phosphate containing starch $0 \cdot 1 \% \mathrm{w} / \mathrm{v}$ and glucose $1 \% \mathrm{w} / \mathrm{v}$.

between pigment obtained aerobically or anaerobically (see below).

\section{Relationship between single- and four-peak pigment}

Cells grown to stationary phase which produced single-peak $(415 \mathrm{~nm})$ pigment in culture supernate were harvested, washed and incubated in a starchglucose extractor solution as for late exponential phase cells. These stationary phase cells then produced four-peak pigment, but no single-peak pigment.

Four-peak pigment formed in the presence of starch was converted to single-peak pigment by removal of the starch. Filtrates containing fourpeak pigment obtained by suspending late exponen-

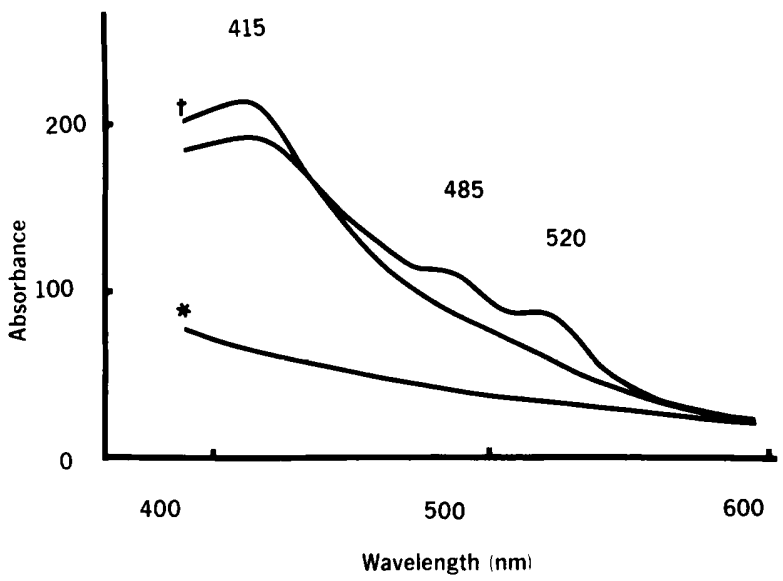

Fig. 4. - Absorbance spectra obtained with filtrates of suspensions of group-B streptococci NCTC 8017 and NCTC $8020^{*}$ incubated in albumin-glucose-PBS extractor solutions. Incubation time $5 \mathrm{~min}$ at $37^{\circ} \mathrm{C}$. After standing for $30 \mathrm{~min}$ at room temperature the absorbance spectrum of material from NCTC 8017 was re-examined. $\dagger$ Note conversion of $520-$ and $485-\mathrm{nm}$ peaks to a 415 -nm peak. tial phase cells in a starch-glucose solution were incubated with a $2 \mathrm{mg} / \mathrm{ml}$ solution of $\alpha$ amylase (type IIa) from Bacillus subtilis, 1355 units/mg (Sigma) at $37^{\circ} \mathrm{C}$. The four-peak pigment was progressively converted to single-peak pigment; the process was complete after $2 \mathrm{~h}$. Boiling the fourpeak preparation for $5 \mathrm{~min}$ converted all the pigment to the single-peak type. Approximately $50 \%$ of the four-peak pigment was converted to the single-peak type by heating the solution at $80^{\circ} \mathrm{C}$ for $1 \mathrm{~h}$. Heating at $60^{\circ} \mathrm{C}$ for $1 \mathrm{~h}$ did not alter the fourpeak pigment. Single-peak pigment was thermostable and amylase resistant.

Single-peak pigment was not converted to fourpeak pigment when attached to starch. A filtrate derived from PBS washings of stationary-phase cells which contained single-peak pigment was incubated with an equal volume of soluble starch $1 \% \mathrm{w} / \mathrm{v}$ in PBS for $30 \mathrm{~min}$ at $37^{\circ} \mathrm{C}$. An equal volume of cold $95 \%$ ethanol was added and the resulting mixture held at $0^{\circ} \mathrm{C}$ for $5 \mathrm{~min}$. A pigmented precipitate formed and, after centrifugation of the mixture, a colourless supernate remained. The precipitate was washed and re-dissolved in PBS and spectrophotometric analysis showed a single absorbance peak at $415 \mathrm{~nm}$. No absorption peak was present on similar analysis of the supernate. Ethanol treatment did not precipitate the single-peak pigment in the absence of starch and the absorption spectrum of single-peak pigment was not altered by exposure to ethanol. Four-peak pigment was also precipitated with ethanol and re-dissolved in PBS. No alteration in the absorption spectrum was observed after this treatment.

With albumin-based extractors, peaks at 520 and $485 \mathrm{~nm}$ were observed in addition to the $415-\mathrm{nm}$ peak after 5- or 15-min incubation periods (fig. 4). These peaks progressively decreased on standing at room temperature $\left(22^{\circ} \mathrm{C}\right)$ and this decrease in higher-wavelength peaks was accompanied by a concomitant and progressive increase in the 415-nm peak, so that after standing for $30 \mathrm{~min}$ the absorption spectrum resembled the one obtained with a 30 min extraction period (fig. 4). The spectrophotometric analysis of four-peak pigment attached to starch, or of single-peak pigment, did not alter on standing in air for $24 \mathrm{~h}$.

\section{Discussion}

The two types of pigment described previously (Merritt and Jacobs, 1976; Haug and Soderlund, 1977) were demonstrated in this study. Both types were found in culture supernate after growth of the organism to stationary phase and the two types 
were also formed and released into solution by suspensions of late-exponential-phase cells. In the presence of soluble starch, whether in the culture medium or in the extractor solution, the four-peak pigment (Merritt and Jacobs, 1976) was detected whereas only the single-peak type of Haug and Soderlund (1977) was found when starch was absent.

During growth in THB, pigment was not detected in culture supernate until the stationary phase of growth. However, suspensions of late-exponentialphase cells formed pigment by what appeared to be an active metabolic process when incubated with an energy source. It seems likely that cells harvested in the exponential phase of growth contain precursors of pigment, the formation of which is completed as cell metabolism continues. In the presence of starch or albumin the pigment formed was released into solution but when these carriers were absent the pigment remained attached to the cells and the colour of the cell deposit deepened. Pigment yields were abolished or reduced by chemical or physical conditions which decreased the metabolic activity of the cells.

In the presence of a carrier, suspensions of lateexponential-phase cells formed and released pigment in the four-peak form. When the carrier molecule was starch, the four-peak form of the pigment was retained, but subsequent removal of starch by the action of amylase or heat resulted in its conversion to the single-peak type. The single-peak pigment could be attached to starch but this process did not alter its absorption spectrum, indicating that the degradation was irreversible. Albumin also acted as a carrier for pigment, but pigment attached to albumin rapidly degraded to the single-peak form on standing. Unless spectrophotometric methods are used, small amounts of single-peak pigment are difficult to distinguish, especially from similarly coloured liquid media. The apparent enhancement of pigment production by starch may well be due to the ability of starch to retain pigment in the more visible four-peak form.

The nature of the group-B streptococcal pigment has not been completely determined although Merritt and Jacobs (1976), on the basis of spectrophotometric findings, suggested that it may be a $\beta$ carotenoid. The observations recorded in the present study are consistent with this hypothesis. Carotenoids attach preferentially to various substances (Davies, 1976) and starch and albumin seem to be preferred to the natural carrier in the cell membrane. Carotenes are also susceptible to alteration and isomerisation with consequent changes in absorption spectra (Davies, 1976). Bacterial carotenoids differ in some respects from plant carotenes (Taylor, 1984). Some bacterial carotenes are incorporated into cell membranes as carotenoproteins (Taylor, 1984) and this author cites several examples where extraction of bacterial pigments has been achieved with aqueous detergents instead of the more usual organic solvents.

Some of the conditions in which washed suspensions of late-exponential-phase cells formed and released pigment into solution were also examined. The presence of $\mathrm{Mg}^{2+}$ increased pigment yields but other divalent cations had no detectable effect. The $p \mathrm{H}$ of the extractor solution also influenced pigment yields confirming earlier observations of Fallon (1974) on the effects of $p \mathrm{H}$ of solid media on pigment production. This influence of $p \mathrm{H}$ helps to explain the earlier finding of Merritt and Jacobs (1978) of the inhibitory effect of glucose in culture media on pigment production. Glucose in culture media promoted a rapid fall in $p \mathrm{H}$ and a lower pigment yield would result. No increase in pigment production was observed in anaerobic conditions and albumin-associated pigment degraded to the single-peak form as rapidly under anaerobic conditions as in air.

The phenomenon of pigment production is a useful criterion for the identification of group-B streptococci and the findings in this study may have an application in this area. There is also current interest in the role of pigment as a virulence factor in group-B streptococcal disease (Nemergut and Merritt, 1983) and in the role of haemolysin and pigment in the pathogenesis of group-B streptococcal infection (Wennerstron et al., in press). This present study establishes further similarities between pigment formation and haemolysin production in group-B streptococci. Simultaneous loss of both properties was recorded in a group-B streptococcus by Lancefield (1934) and Noble et al. (1983) suggested, on epidemiological grounds, that the two properties were closely linked. Merritt and Jacobs (1976) located the pigment in the cell membrane and Tsaihong and Wennerstrom (1983) suggested that lipoteichoic acid of the cell wall is the natural carrier of haemolysin. In this present study, further parallels are established by demonstrating that pigment, like haemolysin (Marchelewicz and Duncan, 1980) is formed and released by an active process by washed cell suspensions, but retains its properties only in the presence of a suitable carrier.

This work was supported by a grant from the Royal Australasian College of Pathologists. Dr G. Colman and staff of the Streptococcal Reference Laboratory Colindale, London provided helpful advice and comment. 


\section{REFERENCES}

Davies B H 1976 Carotenoids. In: Goodwin TW (ed) Chemistry and biochemistry of plant pigments, Vol 2, 2nd edn. Academic Press, London, pp 72 and 139.

Durand P, Giraud P 1923 Les streptocoques chromogènes. Comptes Rendues Hebdomadaires de l'Academie des Sciences, Paris 177:1333-1335.

Fallon R J 1974 The rapid recognition of Lancefield group B haemolytic streptococci. Journal of Clinical Pathology 27:902-905.

Haug R H, Soderlund E 1977 Pigment production in group B streptococci. Acta Pathologica Microbiologica Scandinavica, Section B 85:286-288.

Islam AKMS 1977 Rapid recognition of group-B streptococci. Lancet 1:256-257.

Lancefield R C 1934 Loss of the properties of hemolysin and pigment formation without change in immunological specificity in a strain of Streptococcus haemolyticus. Journal of Experimental Medicine 59:459-469.

Marchelewicz B A, Duncan J L 1980 Properties of a haemolysin produced by group B streptococci. Infection and Immunity 30:805-813.

Merritt K, Jacobs N J 1976 Improved medium for detecting pigment production by group B streptococci. Journal of Clinical Microbiology 4:379-380.

Merritt K, Jacobs N J 1978 Characterization and incidence of pigment production by human clinical group B streptococci. Journal of Clinical Microbiology 8:105-107.
Merritt K, Treadwell T L, Jacobs N J 1976 Rapid recognition of group B streptococci by pigment production and counterimmunoelectrophoresis. Journal of Clinical Microbiology 3:287-290.

Nemergut R A, Merritt K 1983 Neutralisation of oxidative killing by group B streptococcal carotenoid pigment. Abstracts of the Annual Meeting, American Society for Microbiology, Abstract no B32, p 28.

Noble M A, Bent J M, West A B 1983 Detection and identification of group B streptococci by use of pigment production. Journal of Clinical Pathology 36:350-352.

Orla-Jensen S 1919 The lactic acid bacteria. A.F. Host and Son, Copenhagen $\mathrm{p} 135$.

Taylor R F 1984 Bacterial triterpenoids. Microbiological Reviews 48:181-198.

Taylor R F, Davies B H 1974 Triterpenoid Carotenoids and related lipids. The triterpenoid carotenes of Streptococcus faecium UNH 564p. Biochemical Journal 139:751-760.

Tsaihong J C, Wennerstrom D E 1983 Effect of carrier molecules on production and properties of extracellular hemolysin produced by Streptococcus agalactiae. Current Microbiology 9:333-337.

Waitkins S A 1983 A selective and differential medium for group B streptococci. Medical Laboratory Science 39:185-188.

Wennerstrom D E, Tsaihong J C, Crawford J T Evaluation of the role of hemolysin and pigment in pathogenesis of early onset group B streptococcal infection. Proceedings of the IXth Lancefield international symposium on streptococci and streptococcal diseases. Reedbooks, Chertsey (in press). 